\title{
A methodology for outsourcing resources in reverse logistics using fuzzy TOPSIS and fuzzy linear programming
}

\author{
Sajad Mehri $^{\mathrm{a}^{*}}$, Emad Roghanian ${ }^{\mathrm{b}}$ and Tahereh Khodadadzadeh ${ }^{\mathrm{c}}$
}

\begin{abstract}
${ }^{a}$ Department of Industrial Engineering, Science and Research, Arak Branch, Islamic Azad University, Arak, Iran
${ }^{b}$ Department of Industrial Engineering, Khaje Nasir University of Technology, Tehran, Iran

${ }^{c}$ Department of Industrial Engineering (Digital Unit), Iran University of Science \& Technology, Tehran, Iran

CHRON I C L E

\section{A B S T R A C T}

Article history:

Received January 12, 2013

Received in revised format

10 April 2013

Accepted May 212013

Available online

May 272013

Keywords:

Supply chain

Fuzzy linear programming

Fuzzy TOPSIS
One of the primary concerns on supply chain management is to select appropriate suppliers based on different criteria, which are often in serious conflict. In this paper, we present a fuzzy TOPSIS technique to prioritize suppliers on reverse logistic network based on different criteria and then the proposed model of this paper applies fuzzy linear programming technique to determine optimum order quantity associated with each supplier. There are three criteria associated with each supplier including technical skills, equipment and ability to analyze. The implementation of the proposed method has been demonstrated in case study.

\section{Introduction}

Supplier Choosing appropriate supplier plays an important role on having efficient production planning. Ghodsypour and O'brien (1998) are believed to be first who introduced the idea of supplier selection based on a hybrid of multi-criteria decision making and linear programming. Reverse logistics consists of all operations associated with the reuse of products. External suppliers are considered as a reverse logistics and closed loop supply chain (CLSC) networks where suppliers can be evaluated based on purchasing expenditure and other related factors such as on-time delivery, which are often ignored. Hassanzadeh Amin and Zhang (2012) considered a general CLSC network, which includes manufacturer, disassembly, refurbishing, and disposal sites and they are managed by some manufacturers. They proposed an integrated model with two phases: In the first phase, a framework for supplier selection criteria in RL is considered. Besides, a fuzzy method (Bellman \& Zadeh, 1970) was also designed to assess suppliers based on qualitative criteria.

* Corresponding author. Tel: +989124905337

E-mail addresses: sajad_parsian@yahoo.com (S. Mehri)

(C) 2013 Growing Science Ltd. All rights reserved. doi: $10.5267 /$ j.uscm.2013.05.004 
The output of this stage is the weight of each supplier based on each part. In the second phase, they proposed a multi objective mixed-integer linear programming technique to determine which suppliers and refurbishing sites have to be selected (strategic decisions), and determined the optimal number of parts and products in CLSC network (tactical decisions). The objective functions maximized profit and weights of suppliers, and one of them minimized defect rates. This model is one of the first efforts to consider supplier selection, order allocation, and CLSC network configuration, simultaneously.

According to Kannan et al. (2009) return of used products is becoming an essential logistics activity because of government legislation and increasing awareness among the people to have better environment and reduce waste. For industries, the management of return flow often needs a specialized infrastructure with special information systems for tracking equipment for the processing of returns. Therefore, industries are switching to third-party reverse logistics providers (3PRLPs). Kannan et al. (2009) applied a multi-criteria group decision-making (MCGDM) model in fuzzy environment to guide the selection process of best 3PRLP. The interactions among the criteria were investigated before arriving at a decision for the selection of 3PRLP from among 15 different alternatives. The analysis was accomplished through Interpretive Structural Modeling (ISM) and fuzzy technique for order preference by similarity to ideal solution (TOPSIS). They used the proposed method for a case study on battery manufacturing industry in India.

Bottani and Rizzi (2006) presented a multi-attribute technique for the selection and ranking of the most suitable 3PL service provider. They presented a quantitative methodology based on a structured framework, to select the most appropriate 3PL service provider. Chan and Kumar (2007) identified and discussed some of the essential decision criteria including risk factors for the development of an efficient system for global supplier selection. They used fuzzy extended analytic hierarchy process (FEAHP) based methodology to tackle various decision criteria like cost, quality, service performance and supplier's profile including the risk factors involved in the selection of global supplier in the current business scenario. They stated that FEAHP could be an efficient technique to handle the fuzziness of the data involved in deciding the preferences of various decision variables. The linguistic level of comparisons produced by the customers and experts for each comparison were considered in the form triangular fuzzy numbers to build fuzzy pair-wise comparison matrices. The implementation of the system was demonstrated by a problem having four stages of hierarchy, which contains various criteria and attributed at wider perspective. They explained that the proposed model could provide not only a framework for the organization to select the global supplier but also it could be used to deploy the organization's strategy to its supplier.

Chen et al. (2006) presented a fuzzy decision-making technique to deal with the supplier selection problem in supply chain system. They used linguistic values to evaluate the ratings and weights for these factors where the linguistic ratings could be expressed in trapezoidal or triangular fuzzy numbers and the suppliers are ranked based on TOPSIS method. Kim et al. (2006) discussed the remanufacturing process of reusable parts in reverse logistics, where the manufacturer had two alternatives for supplying parts including ordering the required parts to external suppliers or overhauling returned products and bringing them back to 'as new' conditions. They proposed a general framework for this remanufacturing environment and a mathematical model to maximize the total cost savings by optimally deciding the quantity of parts to be processed at each remanufacturing facilities, the number of purchased parts from subcontractor.

Lee et al. (2009) formulated a mathematical model of remanufacturing system as three-stage logistics network model for minimizing the total of costs to reverse logistics shipping cost and fixed opening cost of the disassembly centers and processing centers. Mafakheri et al. (2011) proposed a two-stage multiple criteria dynamic programming technique for two of the most critical tasks in supply chain management, namely, supplier selection and order allocation. 
Meade and Sarkis (2002) presented a conceptual model for selecting and evaluating third-party reverse logistics providers. Wang et al. (2009) presented a new fuzzy hierarchical TOPSIS for supplier selection. Yang and Hung (2007) presented a multiple-attribute decision making methods for plant layout design problem. Bayazit (2006) implemented analytic network process in vendor selection decisions. Sevkli et al. (2008) presented a hybrid analytical hierarchy process model for supplier selection and finally, Humphreys et al. (2003) considered integrating environmental criteria into the supplier selection process.

\section{The proposed method}

The proposed model of this paper uses reverse logistic by considering six perspectives including customer, internal process, human resources, financial affairs, appropriate strategy and external issues. The proposed model of this paper uses linguistic terms to compare different alternatives based on fuzzy method. To do this, we setup a committee to compare various criteria based on AHP. The proposed model of this paper then uses the weights obtained by AHP in a fuzzy TOPSIS technique to rank different suppliers. The weight assigned for each alternative is assigned based on the following fuzzy number,

$$
\tilde{x}_{i j k}=\left(a_{i j k}, b_{i j k}, c_{i j k}, d_{i j k}\right) \quad i=1,2, \ldots . ., m \quad j=1,2, \ldots ., n
$$

Simple arithmetic operations are accomplished as follows,

$\tilde{x}_{i j}=\left(a_{i j}, b_{i j}, c_{i j}, d_{i j}\right)$

$a_{i j}=\min _{k}\left(a_{i j k}\right), b_{i j}=\frac{\sum_{k=1}^{k} b_{i j k}}{k}, c_{i j}=\frac{\sum_{k=1}^{k} b_{i j k}}{k}, d_{i j}=\max _{k}\left(d_{i j k}\right)$

In this paper, we perform normalization policy based on the following technique,

$$
\begin{array}{ll}
\tilde{R}=\left[\tilde{r}_{i j}\right] \\
\tilde{r}_{i j}=\left[\frac{a_{i j}}{d_{j}^{*}}, \frac{b_{i j}}{d_{j}^{*}}, \frac{c_{i j}}{d_{j}^{*}}, \frac{d_{i j}}{d_{j}^{*}}\right], j \in B \\
\tilde{r}_{i j}=\left[\frac{a_{j}^{-}}{d_{i j}}, \frac{a_{j}^{-}}{c_{i j}}, \frac{a_{j}^{-}}{b_{i j}}, \frac{a_{j}^{-}}{a_{i j}}\right], j \in C \\
d_{j}^{*}=\max _{i} d_{i j} \quad, j \in B \\
a_{j}^{-}=\min _{i} a_{i j}, j \in C
\end{array}
$$

When all suppliers are ranked based on fuzzy TOPSIS technique, we may find appropriate order size based a mathematical model as follows,

\subsection{Assumptions}

Indices:

$$
i \text { : } \quad \text { Index for suppliers }
$$

Parameters:

$\begin{array}{ll}n: & \text { Number of suppliers } \\ k: & \text { Number of all product for outsourcing } \\ b_{i}: & \text { Primal Capacity of supplier } i \\ b_{i}+p_{i}: & \text { Secondary Capacity of supplier } i\end{array}$


$\beta$ :

Max percent of loss for all product for outsourcing

$C_{i}^{\prime}:$

$\bar{C}_{i}^{\prime}$ :

Decision variables:

$x_{i}:$

The optimum unit for supplier $i$

$C L_{i}:$ Closeness coefficient of supplier $i$ (obtained from TOPSIS-linguistic)

\subsection{The mathematical model}

The objective function of the proposed model is as follows,

$\max Z_{L}=\sum_{i=1}^{n} C L_{i} X_{i}$

Since we are interested in reaching the positive ideal alternatives we need to have

$\sum_{i=1}^{n} X_{i}=k$

In addition, the amount of return proportion to quality of a supplier for various items must be set as follows,

$\sum_{i=1}^{n} \alpha_{i} X_{i} \leq \beta K$

In addition, we need to consider a predefined budget for each resource allocation as follows,

$\sum_{i=1}^{n} C_{i}^{\prime} X_{i} \leq \bar{C}_{i}^{\prime} K$

We also need to consider a limit for each supplier as follows,

$X_{i} \leq b_{i} \quad, \forall i$

Finally, we have

$X_{i} \geq 0 \quad \alpha_{i}, \beta \in[0,1]$

2.3. The proposed model using fuzzy numbers for $\mathrm{Zu}$

In order to find $\mathrm{Zu}$ for the proposed model we use the following problem formaulation,

$\max Z_{U}=\sum_{i=1}^{n} C L_{i} X_{i}$

subject to

$\sum_{i=1}^{n} X_{i}=k$

$\sum_{i=1}^{n} \alpha_{i} X_{i} \leq \beta k$

$\sum_{i=1}^{n} C_{i}^{\prime} X_{i} \leq \bar{C}_{i}^{\prime} K$ 
$X_{i} \leq b_{i}+p_{i} \quad, \forall i$

$X_{i} \geq 0, \alpha_{i}, \beta \in[0,1]$

2.4. The proposed model using fuzzy numbers for $Z_{l}$

The procedure of $Z_{1}$ is similar to $\mathrm{Zu}$ except for constraint (8) and constraint (14), which are defined as follows,

$G(x)=\left\{\begin{array}{cc}1 & c x \geq z_{u} \\ \frac{c x-z_{l}}{z_{u}-z_{l}} & z_{l} \leq c x \leq z_{u} \\ 0 & c x \leq z_{l}\end{array}\right.$

The optimal value of the proposed fuzzy problem is used by applying an appropriate value of $\lambda$ using the following relationship,

$\max \lambda$

subject to

$$
\begin{aligned}
& \lambda\left(Z_{U}-Z_{L}\right)-C X \leq-Z_{L} \\
& \lambda p_{i}+\sum_{i=1}^{n} X_{i} \leq b_{i}+p_{i} \\
& \sum_{i=1}^{n} X_{i}=k \\
& \sum_{i=1}^{n} \alpha_{i} X_{i} \leq \beta k \\
& \sum_{i=1}^{n} C_{i}^{\prime} X_{i} \leq \bar{C}^{\prime} K \\
& \lambda \geq 0, X_{i} \geq 0, \alpha_{i}, \beta \in[0,1]
\end{aligned}
$$

Note that when the percentage of defected ordered materials generated by suppliers and producers are expressed in fuzzy form, we may have the following problem statement,

$\max Z=\sum_{i=1}^{n} C L_{i} X_{i}$

subject to

$$
\begin{aligned}
& \sum_{i=1}^{n} X_{i}=k, \\
& \sum_{j=1}^{n} a_{i j}^{p} x_{j} \leq b_{i}^{p}, \\
& \sum_{j=1}^{n}\left(a_{i j}^{p}-a_{i j}^{m}\right) x_{j} \leq b_{i}^{p}-b_{i}^{m}, \\
& \sum_{j=1}^{n}\left(a_{i j}^{p}+a_{i j}^{o}\right) x_{j} \leq b_{i}^{p}+b_{i}^{o},
\end{aligned}
$$


and it is an easy to task to convert the resulted problem into an ordinary linear programming problem.

\section{A numerical example}

Consider a supplier selection when there are five alternatives and three decision makers (DMs). Our decision makers consider experience, skills as well as capabilities of different suppliers. In addition, our suppliers consider factors like value added methods, information system, customer satisfaction, environment issues and transportation problems. The implementation of fuzzy TOPSIS for ranking different suppliers in term of these criteria gives relative weights of $0.376,0.514,0.911,0.21$ and 0.627 for suppliers 1 to 5 , respectively. In addition, Table 1 shows other information of suppliers,

Table 1

Input information

\begin{tabular}{cccc}
\hline Supplier & Percent of loss supplier & Cost of supplier for improvement & Primal Capacity of supplier \\
\hline SUP1 & 0.04 & 410 & 150 \\
SUP2 & 0.08 & 430 & 100 \\
SUP3 & 0.01 & 370 & 40 \\
SUP4 & 0.01 & 350 & 80 \\
SUP5 & 0.02 & 390 & 50 \\
\hline
\end{tabular}

The following summarizes the model used to calculate $Z_{1}$ as follows,

$\max z=0.376 x_{1}+0.514 x_{2}+0.911 x_{3}+0.21 x_{4}+0.627 x_{5}$

subject to

$$
\begin{aligned}
& x_{1}+x_{2}+x_{3}+x_{4}+x_{5}=250 \\
& 0.04 x_{1}+0.08 x_{2}+0.01 x_{3}+0.01 x_{4}+0.02 x_{5} \leq 12.5 \\
& 410 x_{1}+430 x_{2}+370 x_{3}+350 x_{4}+390 x_{5} \leq 97500 \\
& x_{1} \leq 150, x_{2} \leq 100, x_{3} \leq 40, x_{4} \leq 80, x_{5} \leq 50, x_{i} \geq 0
\end{aligned}
$$

The optimal solution are $x_{1}=0, x_{2}=90, x_{3}=40, x_{4}=70, x_{5}=50$ with objective function of 128.75 . After some investigation, we have realized that suppliers could expand their capacity as follows,

\begin{tabular}{lccccc}
\hline Supplier & 1 & 2 & 3 & 4 & 5 \\
\hline Capacity & 180 & 120 & 60 & 90 & 60 \\
\hline
\end{tabular}

If we solve the problem with these new capacities, the optimal solution will be changed to 143.9, which is considered as upper bound and the optimal values are $x_{1}=0, x_{2}=80, x_{3}=60, x_{4}=50, x_{5}=60$. Now we solve the following linear programming model,

$\max \lambda$

subject to

$$
\begin{aligned}
& 15.15 \lambda-0.376 x_{1}-0.514 x_{2}-0.911 x_{3}-0.21 x_{4}-0.627 x_{5} \leq-128.75 \\
& x_{1}+x_{2}+x_{3}+x_{4}+x_{5}=250 \\
& 0.04 x_{1}+0.08 x_{2}+0.01 x_{3}+0.01 x_{4}+0.02 x_{5} \leq 12.5 \\
& 410 x_{1}+430 x_{2}+370 x_{3}+350 x_{4}+390 x_{5} \leq 97500
\end{aligned}
$$


$30 \lambda+x_{1} \leq 180, \quad 20 \lambda+x_{2} \leq 120, \quad 40 \lambda+x_{3} \leq 60, \quad 10 \lambda+x_{4} \leq 90$,

$10 \lambda+x_{5} \leq 60, \lambda \geq 0, x_{i} \geq 0$

The optimal value is as follows,

$\lambda^{\text {opt }}=0.353, x_{1}=0, x_{2}=85.3, x_{3}=45.84, x_{4}=62.38, x_{5}=54.46, Z^{\text {opt }}=134.1$.

As we can observe from the results of optimal solution, second supplier receive the highest order followed by the fourth one and the fifth one.

There is also another scenario where suppliers announce their defects in triangular form for supplier 1 to supplier 5 as $(0.03,0.04,0.05),(0.07,0.08,0.09),(0,0.01,0.02),(0.01,0.02,0.03)$. In addition, producer announce its acceptable defect ratio as $(0.04,0.05,0.06)$. The optimal solution can be determined using the following linear programming model,

$\max 0.376 x_{1}+0.514 x_{2}+0.911 x_{3}+0.21 x_{4}+0.627 x_{5}$

subject to

$x_{1}+x_{2}+x_{3}+x_{4}+x_{5}=250$

$0.03 x_{1}+0.07 x_{2}+0 x_{3}+0 x_{4}+0.01 x_{5} \leq 10$

$(0.03-0.04) x_{1}+(0.07-0.08) x_{2}+(0-0.01) x_{3}+(0-0.01) x_{4}+(0.01-0.02) x_{5} \leq-2.5$

$(0.03+0.05) x_{1}+(0.07+0.09) x_{2}+(0+0.02) x_{3}+(0+0.02) x_{4}+(0.01+0.03) x_{5} \leq 25$

$410 x_{1}+430 x_{2}+370 x_{3}+350 x_{4}+390 x_{5} \leq 97500$

$x_{1} \leq 150, x_{2} \leq 100, x_{3} \leq 40, x_{4} \leq 80, x_{5} \leq 50, x_{i} \geq 0$

The optimal solution of the model specified in Eqs. (30) is as follows,

$x_{1}=0, x_{2}=90, x_{3}=40, x_{4}=70, x_{5}=50 \quad Z^{o p t}=128.75$

In this case, the second supplier still receives the highest production followed by the fourth one.

\section{Discussion and conclusion}

In this paper, we have presented a new technique to rank different suppliers based on various criteria using fuzzy TOPSIS technique and the results of ranking have been applied for a fuzzy linear programming to find the optimal quantity of ordering product to various suppliers. The proposed model of this paper has the capability to consider uncertainty in terms of linguistic terms. This paper can be extended to some new open research area by considering uncertainty in terms of uniform function through the implementation of robust optimization techniques and we leave it for interested researchers as future research.

\section{Acknowledgment}

The authors would like to thank Metanir company for financially supporting this project.

\section{References}

Bayazit, O. (2006). Use of analytic network process in vendor selection decisions. Benchmarking: An International Journal, 13(5), 566-579.

Bellman, R. E., \& Zadeh, L. A. (1970). Decision-making in a fuzzy environment. Management science, 17(4), B-141. 
Bottani, E., \& Rizzi, A. (2006). A fuzzy TOPSIS methodology to support outsourcing of logistics services. Supply Chain Management: An International Journal, 11(4), 294-308.

Chan, F. T., \& Kumar, N. (2007). Global supplier development considering risk factors using fuzzy extended AHP-based approach. Omega, 35(4), 417-431.

Chen, C. T., Lin, C. T., \& Huang, S. F. (2006). A fuzzy approach for supplier evaluation and selection in supply chain management. International Journal of Production Economics, 102(2), 289-301.

Ghodsypour, S. H., \& O'brien, C. (1998). A decision support system for supplier selection using an integrated analytic hierarchy process and linear programming. International journal of production economics, 56, 199-212.

Hassanzadeh Amin, S. H., \& Zhang, G. (2012). An integrated model for closed-loop supply chain configuration and supplier selection: Multi-objective approach. Expert Systems with Applications, 39(8), 6782-6791.

Humphreys, P. K., Wong, Y. K., \& Chan, F. T. S. (2003). Integrating environmental criteria into the supplier selection process. Journal of Materials Processing Technology, 138(1), 349-356.

Kannan, G., Pokharel, S., \& Sasi Kumar, P. (2009). A hybrid approach using ISM and fuzzy TOPSIS for the selection of reverse logistics provider. Resources, conservation and recycling, 54(1), 28-36.

Kim, K. B., Song, I. S., \& Jeong, B. J. (2006). Supply planning model for remanufacturing system in reverse logistics environment. Computers \& Industrial Engineering, 51(2), 279-287.

Lee, J. E., Gen, M., \& Rhee, K. G. (2009). Network model and optimization of reverse logistics by hybrid genetic algorithm. Computers \& Industrial Engineering, 56(3), 951-964

Mafakheri, F., Breton, M., \& Ghoniem, A. (2011). Supplier selection-order allocation: a two-stage multiple criteria dynamic programming approach. International Journal of Production Economics, 132(1), 52-57.

Meade, L., \& Sarkis, J. (2002). A conceptual model for selecting and evaluating third-party reverse logistics providers. Supply Chain Management: An International Journal, 7(5), 283-295.

Sevkli, M., Koh, S. L., Zaim, S., Demirbag, M., \& Tatoglu, E. (2008). Hybrid analytical hierarchy process model for supplier selection. Industrial Management \& Data Systems, 108(1), 122-142.

Wang, J. W., Cheng, C. H., \& Huang, K. C. (2009). Fuzzy hierarchical TOPSIS for supplier selection. Applied Soft Computing, 9(1), 377-386.

Yang, T., \& Hung, C. C. (2007). Multiple-attribute decision making methods for plant layout design problem. Robotics and computer-integrated manufacturing, 23(1), 126-137. 